\title{
Web2.0, User Generated Contents, Mobile App and China Travel Company Marketing Positioning Along Consumer Consumption Process- A Case Study from China
}

\author{
A. P. MA
}

Beijing International Studies University, Beijing, China

S.N. KOU

Beijing Mafengwo Technology Company, Beijing, China

L. BAI

Nottingham Trent University, Nottingham, UK

J.R. SUN \& H.J. YUE

Beijing International Studies University, Beijing, China

\begin{abstract}
By discussion the consumption processes of travelers in China, the paper analyses the related products and services offered by different online travel companies in China. Along each stages of traveler product consumption chain, a variety companies on line focusing on different needs such as searching information, sharing information already has its unique logo in consumer mind. The discussion further analyses Mafengwo online travel company as a case study.
\end{abstract}

KEYWORD: Web2.0; User Generated Contents; mobile App; China travel company; consumer consumption process; market positioning; a case study from China

\section{RESEARCH BACKGROUND}

\subsection{Increased Information-based power}

According to Lauren I. Labrecque's research in 2013, in digital age travelers have more demand power and information-based power. First of all, Search engines allowed increased consumer access and choice. Second, Information-based power comes through content production. Through user-generatedcontents, consumers could find "an outlet for selfexpression, extending individual reach, and elevating the potential for individual opinion to influence markets".

\subsection{Mobile uses change asymmetry of information}

Many Chinese people use mobile phone as their daily communication tool, mobile communication changes the relationships between time, space and people, it also changes the asymmetry of information between suppliers and consumers dramatically. Advances in mobile technology and data infrastructure "allow for ubiquitous and nearly instant access to information and resources across digital platforms". The traditional role of middle men between destination suppler and traveler changes due to de-middlemen trend in information age.
How traditional travel service companies can provide real value under new digital age is the major research question for discussion in this paper.

2 TRAVEL CONSUMPTION PROCESS AND RELATED PRODUCT OFFERINGS IN CHINA

\subsection{Trend of "de-packaging" in China online travel industry}

There is a "de-packaging" trend in China online travel service providers towards traditional offline traditional travel service companies in China. As Chinese travelers become more individualized in choosing travel-related products, many innovative online travel services exist online by providing different product and services traveler needed. Fierce competition makes these online companies provide different niche services along the consumer's consumption process. This phenomenon is new and few through research on this area yet in China.

\subsection{Stages, services and companies in traveler's consumption process}

One discussion divided traveler's consumption process into several stages, along which a variety of products are offered and different companies exists (Figure1). Figure1 illustrates the different stages of traveler consumption and related necessity online and the related Chinese typical online Chinese companies with their Chinese character 
Consumption processes are divided into the following stages: product and service desire, planning, searching, booking and reservation, at destination, on route, comment and sharing. Accompany the consumption process, the related function of product and services are provided such as microblogs. The representative companies are: mafengwo.com for sharing stage, Qunar.com for searching stage, tuniu.com at booking, Ctrip.com, tongcheng.com getting commission by providing reservations, lumama.com for product selling for destinations, with eHi Car Service for on route stage services, Lvping.com, daodao.com with travel comments and mafengwo.com through user generated content to fulfill the comment functions for travelers.

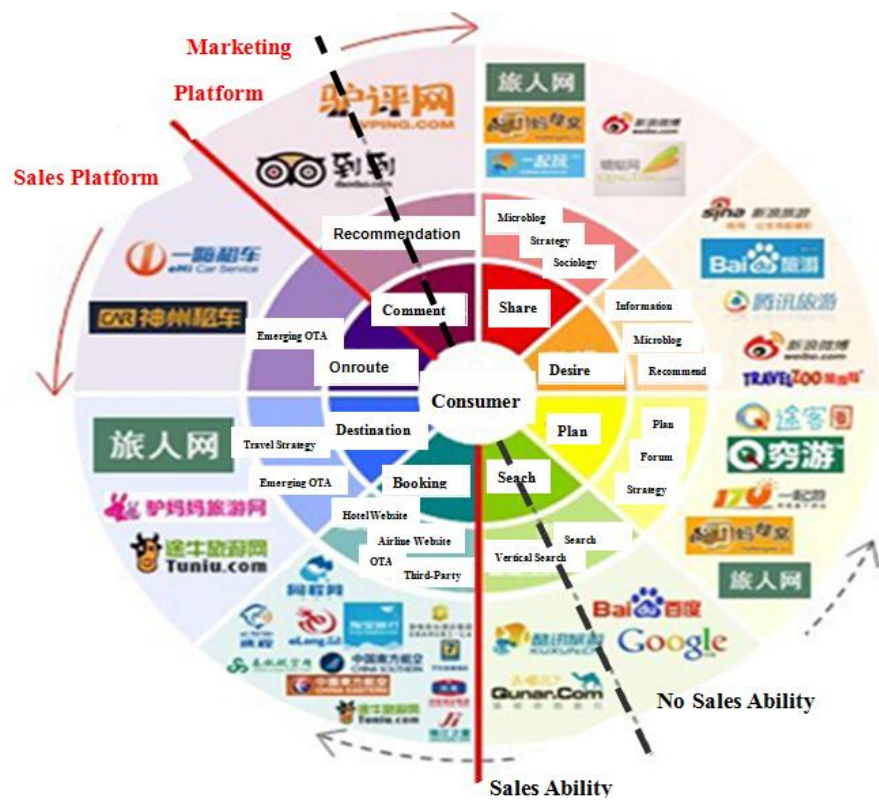

Figure1: Changing purchasing method: online tourism market breakthrough.

Source: http://back.adquan.com/article1.php?id=16926.

\section{BEIJING MAFENGWO NETWORK TECHNOLOGY COMPANY-A CASE STUDY FROM CHINA}

\subsection{Mafengwo's postioning}

Mafengwo owns the largest users among online travel community based travel websites in China.

In 2006, mafengwo positioned itself: sharing travel tips and stories from traveler themselves at market. It is content provided comes from two million active online travel users by providing more than two billion travel experiences and tips. Mafengwo classified its content into different hot topics and guide the interactive among users, the company also develop its effective app such as travel translators, making those tips movable anywhere when travelling.
Customers emphasize two dimension for their consumption, one is price, the other is their product interest. For price, some company provide price comparing service online. For interest dimension, baidu provide destination information. Mafengwo satisfied customers by providing comments for sharing by tourists themselves and the information open to the public.

\subsection{Mafengwo's development}

In 2006, Mafengwo did not earn money, until 2010, the gathering of mass users attracts the attention of risk investors and the company gets its financial support from risk investors twice in 2011 and 2013.

From 2012, Mafengwo started to introduce online web advertisement strategy. One target is for the destination promotions from airline and country tourism bureaus and travel companies such as Australia, Holland tourism bureau and Disneyland. It is a good start.

The other category is cooperative marketing by bringing its customers to the related online company websites such as Ctrip. Mafengwo not only has its promotion on Wechat and microblog, it also open its official account on the popular software "line".

Mafengwo right now is very active in consumer behavior study on big data platform.

In the future, the company want to provide more personalized services as the self- help travel services now already consists more $60 \%$ now in China.

\section{ACKNOWLEDGMENTS}

This article is part of the works of tourism branding, art performance and tourism international communication strategy programs. The sponsorship and support comes from research programs: Beijing Tourism Branding Building, 395002(3), Beijing Cultural Performance Industry and Tourism Industry (14JGB026) and Beijing Tourism International Image Integrated Marketing and Communication Strategy (395001).

\section{REFERENCES}

[1] Lauren I. Labrecque \& Jonas vor dem Esche \& Charla Mathwick \&Thomas P. Novak \& Charles F. Hofacker, Consumer Power: Evolution in the Digital Age, Journal of Interactive Markeing,27(2013):257-269.

[2] Pradeep Racherla, Wesley Friske, Prceived 'usefulness' of online consumer reviews: An exploratory investigation across three services categories, Electronic Commerce Research and Applications, 11 (2012): 548-559. 